\title{
Radiological and Pathological Characteristics of Mandibular Cystic Lesion - A Review
}

\author{
Janardhanam Dineshshankar, M.D.S ${ }^{1}$, Sahuthullah Yasmeenahamed, M.D.S ${ }^{2}$, \\ Nalliappan Ganapathy M.D. $S^{3}$, Shivakumar Sivaraman, M.D. $S^{4}$, \\ ${ }^{I}$ Reader, Department of Oral and Maxillofacial Pathology, Vivekanandha Dental College for Women \\ ${ }^{2}$ Reader, Department of Oral Medicine and Radiology, Vivekanandha Dental College for Women \\ ${ }^{3}$ Professor \& Head, Department of Oral and Maxillofacial Pathology, Vivekanandha Dental College for \\ Women \\ ${ }^{4}$ Senior Lecturer, Department of Oral Medicine and Radiology, Vivekanandha Dental College for Women
}

\begin{abstract}
Many lesions that occur in the jaw have a similar radiological appearance and it is often difficult to differentiate among them. Cysts that are present in the mandible are commonly noted on head and neck imaging and present a diagnostic dilemma. These lesions are often identified as incidental lesions by the radiologist on imaging performed for different reasons. Collaborative interaction between the dentists, oral surgeon, radiologist and oral pathologist is essential for the appropriate evaluation, imaging, and treatment of cystic appearing lesions of the mandible.
\end{abstract}

Keywords: Cyst of mandible, imaging, CT, MRI

\section{Introduction}

Even after development of many modern imaging modalities, radiography still remains the most important mode of investigation for the evaluation of jaw lesions. A variety of cystic lesions occur within the mandible ${ }^{1}$. Although the radiologic findings in some mandibular lesions may be nonspecific, there are often clues for histologic diagnosis within the anatomy surrounding each lesion. In many cases, correct diagnosis is achieved by the clinical history alone ${ }^{2}$. Precise radiologic evaluation of a lesion can have a significant impact on diagnosis and subsequent patient treatment ${ }^{1}$. In this article, we will review the process of odontogenesis, radiologic illustration and pathologic findings in various cystic lesions of mandible to aid in narrowing the differential diagnosis.

\section{Odontogenesis}

Odontogenesis is development of teeth: odont- tooth and genesis-origin. The first brachial arch forms the mandible during the fourth week of embryologic development by means of fusion of the bilateral mandibular prominences ${ }^{3}$. These structures eventually give rise to the teeth through a process called odontogenesis. Each tooth develops from ectodermal cells that develop into ameloblasts and other outer tooth regions, and ectomesenchymal cells that form the odontoblasts and dental papillae. The process begins at the crown of the tooth and continues toward the $\operatorname{root}^{4}$. Three stages of odontogenesis have been described, including the bud, cap, and bell ${ }^{3}$. During the sixth week of intrauterine life, mesenchymal cells thicken and produce the primary dental lamina. These cells start to invaginate to form a tooth bud with an overlying cap. By the 20th week of intrauterine life, the tooth bud appears bell shaped with active odontoblastic and ameloblastic cells. Ameloblastic cells produce enamel, whereas odontoblastic cells produce the dentin. The production of enamel requires the complete formation of the dentin. These processes are completed during the crown stage, as the tooth enters the final stage of development ${ }^{4}$.

Before the completion of odontogenesis, both the primary and secondary dental lamina disappears. Any remnants of these embryonic cells may give rise to cystic lesions as well as benign and malignant lesions later in the life. The remaining ectomesenchymal cells surrounding a tooth create the dental sac, which form the periodontal ligament and cementum. A thin fibrous periodontal ligament attaches the cementum of each tooth to the surrounding alveolar bone (lamina dura) ${ }^{3}$. This highly vascularised connective tissue allows limited motion of each tooth during mastication and also serves to provide sensation. Then the teeth migrate into the oral cavity, and the developmental process is complete ${ }^{4}$ But few remnant cells may persist even after the degeneration of dental lamina. These remnants may be seen in the connective tissue of gingival or in the jaw bones and are named as "cell rest of serres". These cell rests may proliferate under certain conditions giving rise to odontogenic cyst and odontogenic tumours. Odontogenic cyst occurring in the mandible is common so knowing the process of odontogenesis will give a clear cut idea of its cause ${ }^{3,4}$. 


\section{Cystic Lesions}

Cysts commonly occur in the mandible and appear as unilocular or multilocular radiolucencies on dental radiographs. Cystic lesions within the mandible can cause bony remodeling that can weaken the bone, leading to functional changes and predisposing the patient to infection and pathologic fracture ${ }^{5}$. The relationship of the cyst to adjacent structures is important, which includes features such as unerupted teeth, tooth displacement, root resorption, and canal displacement ${ }^{5}$.

A true mandibular cyst forms when developmental or inflammatory factors stimulate proliferation of epithelial cells surrounding a tooth. As the cells grow, their nutrient supply to the central cells is removed and vascular connective tissue become necrotic. Subsequently, a sac or an epithelium-lined cavity is formed ${ }^{6}$.

Mandibular cysts appear radiologically as well-defined lucent areas within the bone. Although sclerotic rim is present in most cysts, because of severe underlying inflammation there will be decrease in the degree of sclerosis ${ }^{7}$. Classifications of cysts (TABLE: 1) done here is by its prevalence and with most of cysts in the mandibular jaw arising from odontogenic sources. However, cysts may also arise from prior trauma or surgery. The wide variation in the frequency with which various cystic lesions occurs often helps narrow the differential diagnosis ${ }^{5}$. Here we will be discussing about the cyst that occurs commonly in the mandible and few other mandibular cysts are excluded because it's very less prevalence in the mandible.

Table 1: According to the Prevalence, Cyst of Mandibular Lesions ${ }^{6,8}$ :

\begin{tabular}{|l|l|l|}
\hline Most common & Fairly common & Rare \\
\hline Radicular cyst & Odontogenic keratocyst & Calcifying odontogenic cyst \\
\hline Residual cyst & Static bone cavity (Stafne cyst) & Aneurysmal bone cyst \\
\hline Dentigerous cyst & Solitary bone cyst & \\
\hline
\end{tabular}

Table 2: Radiographic investigations for cystic lesions ${ }^{6,7,8}$ :

\begin{tabular}{|c|c|c|c|c|}
\hline \multirow[t]{2}{*}{ Cystic Lesions } & \multirow[t]{2}{*}{ Initial Radiographic Imaging } & \multicolumn{3}{|c|}{ Additional Radiologic Evaluation } \\
\hline & & CT & MRI & $\mathrm{PET} / \mathrm{CT}$ \\
\hline Radicular cyst/ Residual Cyst & $\begin{array}{l}\text { Intraoral and panoramic } \\
\text { radiography }\end{array}$ & $\begin{array}{l}\text { Extent of cyst, adjacent } \\
\text { tooth } \\
\text { involvement, preoperative } \\
\text { planning }\end{array}$ & & \\
\hline Dentigerous cyst & $\begin{array}{l}\text { Intraoral and panoramic } \\
\text { radiography }\end{array}$ & $\begin{array}{l}\text { Extent of cyst, adjacent } \\
\text { tooth } \\
\text { involvement, preoperative } \\
\text { planning }\end{array}$ & $\begin{array}{l}\text { NR; can } \\
\text { differentiate } \\
\text { from } \\
\text { ameloblastoma } \\
\text { if } \\
\text { lesions have } \\
\text { overlapping } \\
\text { features }\end{array}$ & \\
\hline Odontogenic Keratocyst & $\begin{array}{l}\text { Intraoral and panoramic } \\
\text { radiography }\end{array}$ & $\begin{array}{l}\text { Extent of disease, presence } \\
\text { of } \\
\text { daughter cysts }\end{array}$ & $\begin{array}{l}\text { Help } \\
\text { differentiate } \\
\text { from } \\
\text { ameloblastoma; } \\
\text { can } \\
\text { suggest } \\
\text { malignant } \\
\text { transformation } \\
\text { into SSC }\end{array}$ & $\begin{array}{l}\text { Staging of } \\
\text { disease } \\
\text { especially if } \\
\text { SSC } \\
\text { transformation }\end{array}$ \\
\hline $\begin{array}{l}\text { Simple bone cyst } \\
\text { (traumatic bone cyst) }\end{array}$ & $\begin{array}{l}\text { Intraoral and panoramic } \\
\text { radiography }\end{array}$ & None typically required & & \\
\hline $\begin{array}{l}\text { Static bone cavity } \\
\text { (Stafne cyst) }\end{array}$ & $\begin{array}{l}\text { Intraoral and panoramic } \\
\text { radiography }\end{array}$ & $\begin{array}{l}\text { If atypical features present, } \\
\text { can aid in exclusion of } \\
\text { other } \\
\text { cystic lesions }\end{array}$ & $\begin{array}{l}\text { If atypical } \\
\text { features } \\
\text { present, can } \\
\text { exclude simple } \\
\text { bone cyst and } \\
\text { ameloblastoma }\end{array}$ & \\
\hline
\end{tabular}

\section{Radicular Cyst}

It is also called as periapical cysts or apical periodontal cysts are the most common odontogenic cysts ${ }^{7}$. Infection in the tooth leads to necrosis of the pulp cavity and it spreads to the tooth apex with ulterior development of a periapical granuloma or periapical abscess. These may later give rise to a radicular cyst ${ }^{8}$. It is 
arise from epithelial cell rests of periodontal ligament, which are accelerated by the inflammatory mechanism. Most often, they are asymptomatic. It may be seen in all age groups, but, more frequently between 30 and 60 years of age which are often associated with a non-vital tooth. Radiographic features are straightforward and have a well-defined unilocular periapical lesion, with sclerotic borders in close proximity to the apical portion of the root in non-vital tooth (fig 1). No contrast material enhancement is seen on CT or MRI. With latero-dental location, CT or CBCT is very helpful for the correct diagnosis of atypical cases (fig: 2) ${ }^{9}$. Almost all radicular cysts are lined totally or partially by stratified squamous epithelium. It may be discontinuous and range of about 6-20 cell layers thick. The epithelial lining may be proliferative and show arcading with an intense associated inflammatory process but as the cyst enlarges the lining becomes quiescent and fairly regular with a certain degree of differentiation to resemble a simple stratified squamous epithelium ( Fig: 3 ). ${ }^{10}$

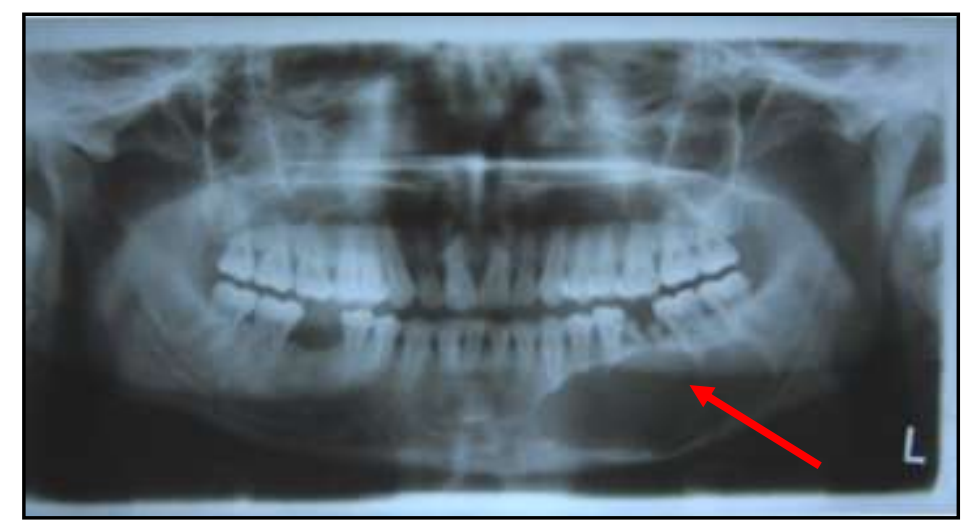

Fig 1: Arrow shows well defined radiolucency seen at the apex of 36 which is more than $3 \mathrm{~cm}$ suggestive of radicular cyst

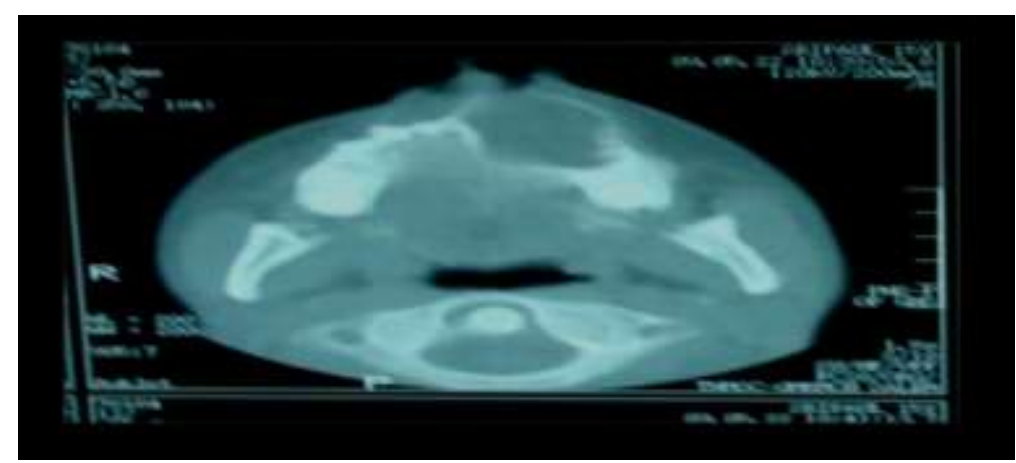

Fig 2: CT axial section showing well defined radiolucency involving maxilla

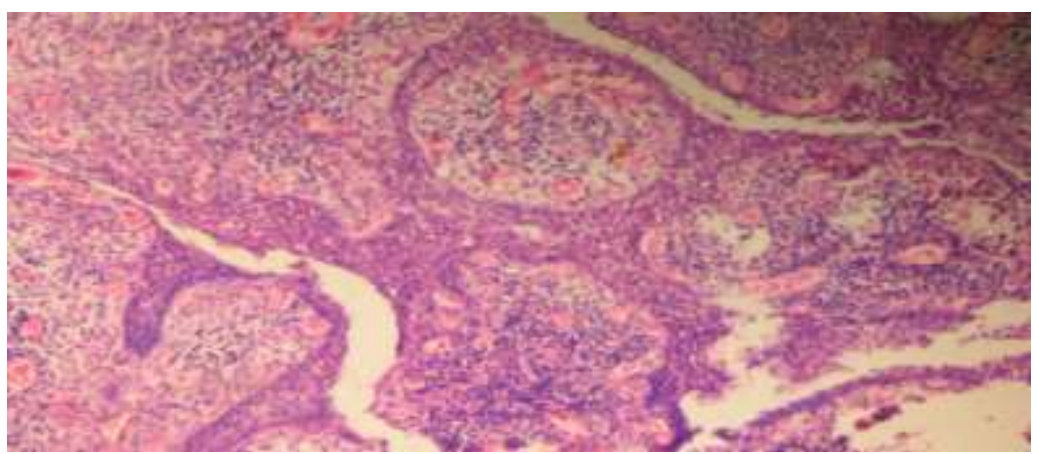

Fig 3: It shows proliferation of epithelium, arcading pattern with an intense associated inflammatory cells are seen

\section{Residual Cyst}

Residual cysts are periapical cysts retained in the jaw after surgical removal of a non-vital tooth. Residual cysts are common and have similar clinical and radiological features as that of radicular cyst. It is always associated with a missing tooth. Size of residual cysts is usually less than $1 \mathrm{~cm}$. Sometimes, enlarging cysts may lead to displacement of the adjacent teeth, as well as bone expansion ${ }^{9}$. The histopathological features 
of the residual cyst are similar to those described above for conventional radicular cyst. Nevertheless the cause of the cyst has been removed; it may gradually become less inflamed so that eventually the cyst wall is composed of uninflamed collagenous fibrous tissue. The epithelial lining may be thin and regular and indistinguishable from a developmental cyst such as a dentigerous cyst or lateral periodontal cyst. ${ }^{10}$

\section{Dentigerous Cyst}

It is the second most common odontogenic mandibular cysts and the most common odontogenic developmental cysts. They are mainly seen in patients with 20-40 years of age. The fluid accumulates between remnants of enamel organ and the tooth crown of the unerupted tooth (most commonly in the lower third molar) 1. Imaging features are characteristic which include a well-defined unilocular radiolucent lesion with sclerotic borders around an unerupted tooth crown. Small follicular cysts may be tough to differentiate from a normal dental follicle (fig 3). It has been suggested that if the distance between the dental sac and the crown is more than $3 \mathrm{~mm}$, the diagnosis of a follicular cyst should be made. It is mostly attached to the neck of the displaced and the unerupted tooth, and the crown commonly protrudes into the cyst while the roots remain outside the lesion (fig 4). It may become very large and may remodel the mandible, predisposing the patient to the infections and even pathological fracture ${ }^{11,12}$. They may thin the cortical layer of the mandible and may be seen around the mandibular canal, which makes surgical excision delicate ${ }^{13}$. CT and CBCT are used to determine the relationship of the unerupted tooth with the cyst to the mandibular canal and maxillary sinus prior to surgery and to assess cyst contents and the integrity of the cortical rim ${ }^{14,15}$ (fig: 5). MRI is indicated only in atypical cases to differentiate follicular cysts from other cystic mandibular lesions ${ }^{12}$. It will often be found accidentally in patients undergoing head and neck MRI for other reason. MRI findings include variable signal intensity on T1 due to variable protein content seen within the cyst, high signal on T2 and sometimes slight enhancement of the thin cyst wall. In spite most cysts show no significant FDG uptake on PET/CT and mild tracer uptake may be present during the infection or inflammation ${ }^{16}$. On histological examination it usually shows a thin fibrous cyst wall which is derived from the dental follicle and consists of young fibroblasts widely separated by stroma and ground substance. Characteristically epithelial lining is of reduced enamel epithelium and it is non-keratinised in nature. It consists of $2-4$ cell layers of flat or cuboidal cells (Fig: 6). ${ }^{10}$

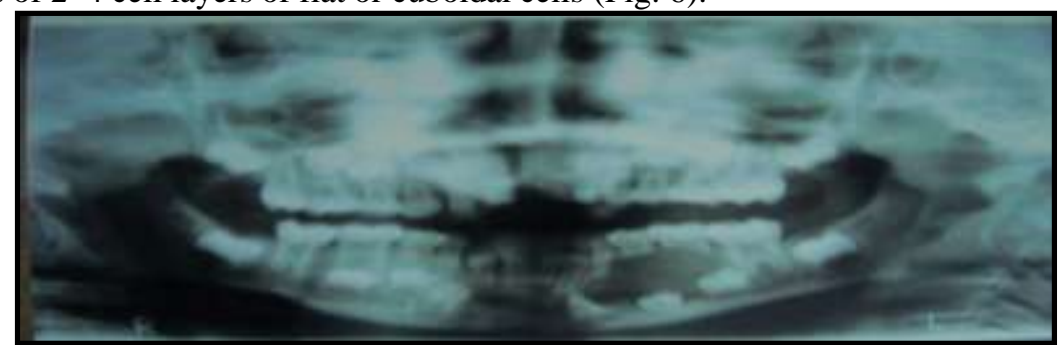

Fig 4: Yellow arrow indicates tooth follicle which is less than $3 \mathrm{~mm}$. Red arrow indicates well defined radiolucency arising from neck of impacted premolar which is more than $1.5 \mathrm{~cm}$ suggestive of dentigerous cyst

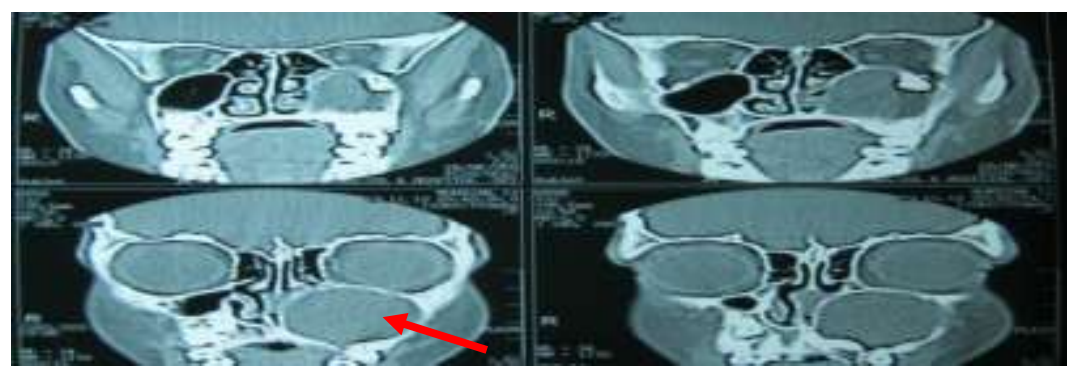

Fig: 5. CT coronal section showing cystic lesion extending into maxillary sinus

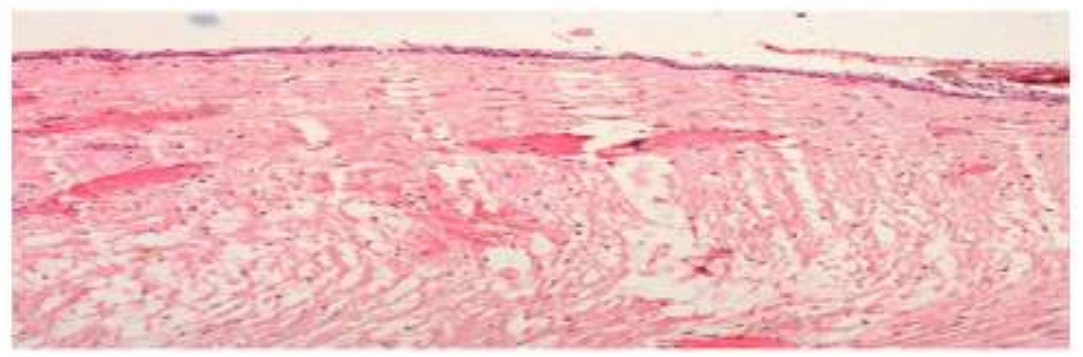

Fig 6: shows epithelial lining of 2-4 cell layers of flat or cuboidal cells with a fibrous cyst wall and young fibroblasts 


\section{Odontogenic Keratocyst}

It is also called keratocystic odontogenic tumours (KCOTs) as per WHO 2005, but still there is controversies going on regarding its name so here we are using the name as Odontogenic Keratocyst (OKC). $\mathrm{OKC}$ are most commonly seen in the body or ramus of the mandible. Mainly, OKCs possess destructive potential, and have a high recurrence rate after resection ${ }^{7}$. It develops from the dental lamina, which is found in the jaw and overlying alveolar mucosa and lined by stratified keratinizing squamous epithelium. Thus, the cysts can be found throughout periapical or primordial regions ${ }^{17}$. Unlike follicular cysts, OKCs can expand cortical bone and erode the cortex with scalloping borders (fig 7). The malignant transformation of these lesions is rare. The lesion is multiloculated, usually with daughter cysts that extend to the surrounding bone. The adjacent teeth resorption is very rare; nevertheless, when this is the case, differentiation from ameloblastoma may be very difficult on $\mathrm{CT}$, OPT or $\mathrm{CBCT}^{18,19}$. It contain a cheese-like material and typically show soft tissue density (up to $50 \mathrm{HU}$ ) on CT (Fig: 8), while on MRI, because of the variable protein content, a low to high signal intensity can be seen on $\mathrm{T} 1$, a heterogeneous signal on $\mathrm{T} 2$. $\mathrm{T} 2$ relaxation times in $\mathrm{OKC}$ have been reported to be shorter than in ameloblastoma ${ }^{19,}{ }^{20}$. Weak enhancement of the uniformly thin and the regular cyst walls is noted after injection of gadolinium chelates, it is helpful from differentiating from ameloblastoma ${ }^{21,22}$. Young patient with Multiple OKCs should raise the possibility of basal cell nevus syndrome. Associated findings with this autosomal dominant disorder include frontal bossing, prognathism, midface hypoplasia, mental retardation, and calcification of the falx cerebri ${ }^{20,23,24}$. Histologically it shows the cysts which are lined by a regular, narrow, keratinised, and stratified squamous epithelium. Thickness of the epithelium is about 5-8 cell layers thick and there will be absence of rete ridges. Mostly parakeratinisation is present in (80-90\%) of cases, but sometimes orthokeratinisation $(8-13 \%)$ and even combination para and orthokeratinisation (1\%) is also seen. Usually it is a well-defined, often palisaded basal layer consisting of columnar or cuboidal cells or a mixture of both (Fig: 9). ${ }^{21}$, 25

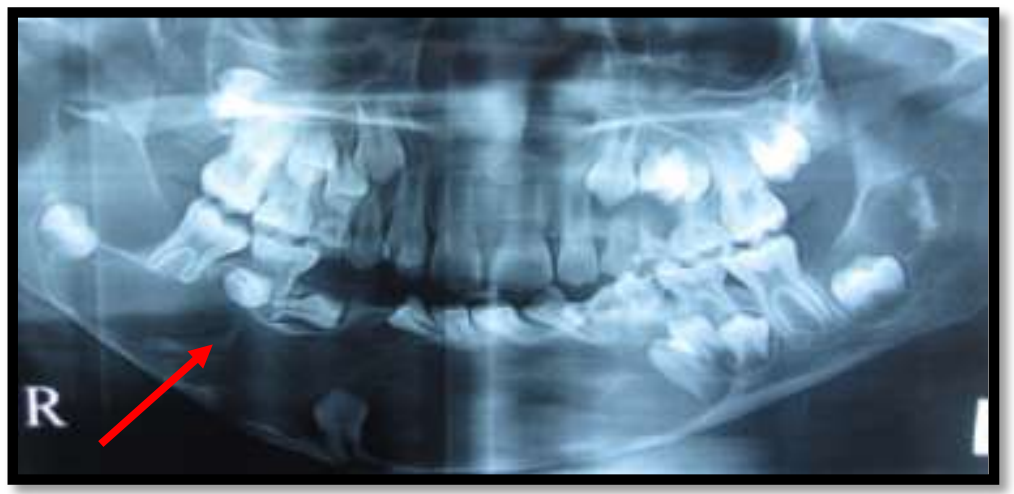

Fig 7: Multiple multilocular radiolucencies seen in relation to impacted teeth with scalloped borders

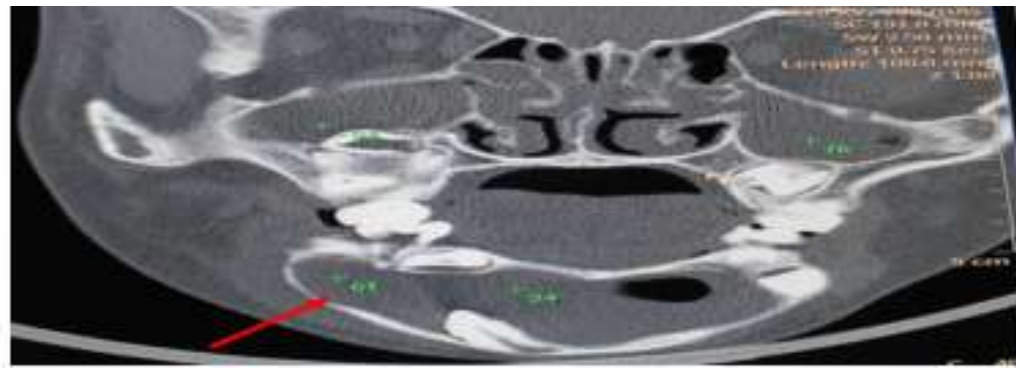

Fig: 8. CT coronal section reveals at the level of the symphysis region, the lesion is approximately $7 \times 3 \mathrm{~cm}$ in size, roughly oval in shape, well defined periphery with thinning of cortex.

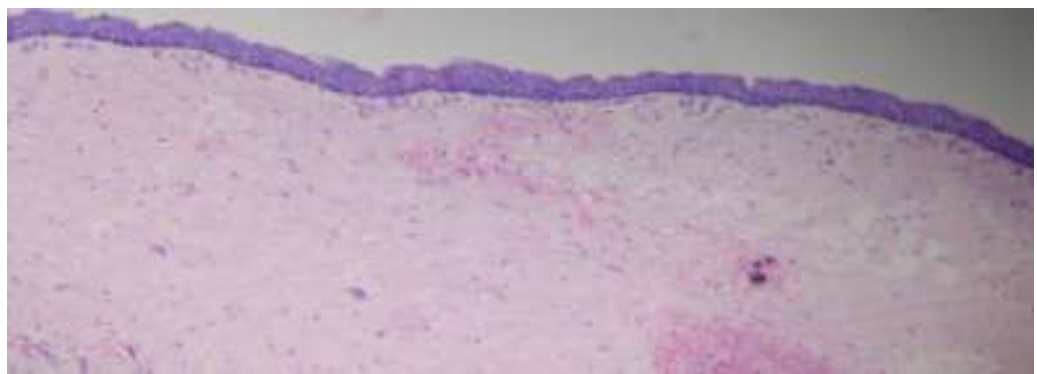

Fig 9: Shows stratified, squamous epithelium of 5-8 cell layers and palisaded, basal layer is seen 


\section{Simple bone cyst}

It is also known as traumatic bone cyst, solitary bone cyst; haemorrhagic cyst or idiopathic bone cavity is filled with serous or haemorrhagic fluid and which is characterised by the absence of an epithelial lining ${ }^{26,27}$. Simple bone cyst (SBC) is not a true cyst but preferably a pseudocyst. SBC of the mandible usually occur secondary to trauma, mainly after tooth extraction with subsequent intramedullary haemorrhage ${ }^{27,28,29}$. It is commonly present before the age of 20 , and usually occurs in female. Of about $75 \%$ of cases, they are seen in the marrow of the posterior mandible. Most lesions are found incidentally on dental radiographs and they are asymptomatic in nature ${ }^{30}$. It occurs in close proximity to a vital tooth and bone swelling is usually very rare unless there is any associated infection ${ }^{18}$. Surgical exploration may be needed in selected cases to exclude from other unilocular radiolucent lesions like keratocysts ${ }^{29,31}$. Imaging features suggest that it will appear as welldefined unilocular radiolucent lesions that may vary in size. Sometimes rarely, poorly defined borders can be $\operatorname{seen}^{32}$. Extension to the cortical bone is usually rare and there is no tooth displacement. The superior margins are irregular and scalloped around roots. CT and MRI can give information on the haemorrhagic content but the density or signal intensity may vary depending on the age of the haemorrhage ${ }^{29,31}$. On MRI, SBC displays a T1 have a homogeneous intermediate signal, whereas $\mathrm{T} 2$ have a homogeneous high signal and no enhancement after injection of intravenous contrast media ${ }^{15,30}$. Histologically it shows loose vascular fibrous connective tissue membrane of variable thickness with the absence of epithelial lining, although fragments of fibrin with enmeshed red cells may be present. There will a presence of haemorrhage and haemosiderin pigments which are scattered, small multinucleate cells are often found. Few cyst walls, possibly a long standing case, are more densely fibrous. If adjacent bone is included it shows osteoclastic resorption on its inner surface. ${ }^{8,32}$

\section{Stafne cyst}

It is also called static bone cavity or salivary gland inclusion defect. Stafne cyst is a pseudocyst arising from bone remodelling caused by the adjacent submandibular gland. Therefore, it does not have an epithelial lining ${ }^{1,33,34}$. They are often incidental findings, as the patients are asymptomatic. It is more common in men than in women. The radiological features include ovoid, well-defined radiolucent cortical defects on the lingual surface of the posterior mandible measuring less than $2 \mathrm{~cm}^{34,35}$. Location is typical and the lesion contains fat or salivary gland tissue. An OPT is sufficient for diagnosis but sometimes CT or MRI can be performed in cases of atypical presentation to exclude it from an ameloblastoma or a traumatic bone cyst. ${ }^{8,36}$

\section{Conclusions}

Cystic Lesions of the mandible arise from both odontogenic and nonodontogenic sources with a variety of both cystic and solid appearances. Given the extensive range of pathologic features but similar imaging findings, familiarity with the embryologic characteristics and secondary imaging findings is crucial. Moreover, the prevalence and location in the mandible of a particular lesion of will helpful in differentiating it from other pathologic conditions. Imaging is not always expected to provide a specific diagnosis but should help narrow the differential diagnosis, thereby helping to guide patient treatment.

\section{References}

[1]. Dunfee BL, Sakai O, Pistey R, Gohel A. Radiologic and pathologic characteristics of benign and malignant lesions of the mandible. Radiographics 2006; 26:1751-1768

[2]. Preece JW. Dental radiographic techniques and normal roentgen anatomy. Semin Roentgenol 1971; 6:359-369.

[3]. Avery JK, Steele PF. Essentials of oral histology and embryology: a clinical approach. St. Louis, MO: Mosby, 2000:53-70

[4]. Abrahams JJ, Rock R, Hayt MW. Embryology and anatomy of the jaw and dentition. In: Som PM, Curtin HD, eds. Head and neck imaging, 4th ed. St. Louis, MO: Mosby, 2003:889-901

[5]. Weber AL, Kaneda T, Scrivani SJ, Aziz S. Jaw: cysts, tumors and nontumorous lesions. In: Som PM, Curtin HD, eds. Head and neck imaging, 4th ed. St. Louis, MO: Mosby, 2003:930-994

[6]. Yoshiura K, Weber AL, Scrivani SJ. Cystic lesions of the mandible and maxilla. Neuroimaging Clin N Am, 2003; 13(3):485-494

[7]. Neyaz Z, Gadodia A, Gamanagatti S, Mukhopadhyay S. Radiographical approach to jaw lesions. Singapore Med J, 2008; 49(2): $165-177$

[8]. Scholl RJ, Kellett HM, Neumann DP, Lurie AG. Cysts and cystic lesions of the mandible: clinical and radiologic-histopathologic review. Radiographics, 1999; 19:1107-1124

[9]. Eversole LR, Rovin S. Differential radiographic diagnosis of lesions of the jawbones. Radiology 1972; 105:277-284

[10]. Shear M. Developmental odontogenic cysts. An update. J Oral Pathol Med 1994; 23: 1-11.

[11]. Freitas DQ, Tempest LM, Sicoli E, Lopes-Neto FC. Bilateral dentigerous cysts: review of the literature and report of an unusual case. Dentomaxillofac Radiol 2006; 35:464-468

[12]. Edamatsu M, Kumamoto H, Ooya K, Echigo S: Apoptosis related factors in the epithelial components of dental follicles and dentigerous cysts associated with impacted third molars of the mandible. Oral Surgery, Oral Medicine, Oral Pathology, Oral Radiology and Endodontics, 2005; 99: 17-23.

[13]. Stathopoulos P, Mezitis M, Kappatos C, Titsinides S, Stylogianni E. Cysts and tumors associated with impacted third molars: is prophylactic removal justified? J Oral Maxillofac Surg. 2011; 69:405-408

[14]. Zhang LL, Yang R, Zhang L, Li W, MacDonald-Jankowski D, Poh CF. Dentigerous cyst: a retrospective clinicopathological analysis of 2082 dentigerous cysts in British Columbia, Canada. International Journal of Oral and Maxillofacial Surgery. 2010; 39 : $878-882$ 
[15]. Khambete N, Kumar R, Risbud M, Kale L, Sodhi S. Dentigerous cyst associated with an impacted mesiodens: report of 2 cases. Imaging Science in Dentistry. 2012; 42: 255-260.

[16]. MinamiM, Kaneda T, Ozawa K, Yamamoto H, Itai Y, OzawaM et al. Cystic lesions of the maxillomandibular region: MR imaging distinction of odontogenic keratocysts and ameloblastomas from other cysts. AJR Am J Roentgenol 1996; 166:943-949

[17]. Nohl FSA, Gulabivala K. Odontogenic keratocyst as periradicular radiolucency in the anterior mandible. Oral Surg Oral Med Oral Pathol Oral Radiol Endod 1996; 81: 103-109.

[18]. Theodorou SJ, Theodorou DJ, Sartoris DJ. Imaging characteristics of neoplasms and other lesions of the jawbones. Part 1. Odontogenic tumors and tumor like lesions. Clin Imaging 2007; 31:114-119

[19]. Boffano P, Ruga E, Gallesio C. Keratocystic odontogenic tumor (odontogenic keratocyst): preliminary retrospective review of epidemiologic, clinical, and radiologic features of 261 lesions from University of Turin. J Oral Maxillofac Surg 2010;68(12):29942999.

[20]. Lindeboom JA, Kroon FH, de Vires J, van den Akker HP. Multiple recurrent and de novo odontogenic keratocysts associated with oral-facial-digital syndrome. Oral Surg Oral Med Oral Pathol Oral Radiol Endod 2003; 95:458-462

[21]. Ali M, Baughman RA. Maxillary odontogenic keratocyst. J Am Dent Assoc 2003 134:877-883

[22]. Giuliani M, Grossi GB, Lajolo C, Biscegila M, Herb KE: Conservative management of a large odontogenic keratocyst: Report of a case and review of literature. Journal of Oral \& Maxillofacial Surgery, 2006; 64(2):308- 316.

[23]. Gonzalez-Alva P, Tanaka A, Oku Y, Yoshizawa D, Itoh S, Sakashita H, Idle F, Tajima Y, Kusama K: Keratocystic odontogenic Tumor: A retrospective study of 183 cases. Journal Of Oral Science, 2008; 50 (2): 205-212.

[24]. Shear M: Odontogenic keratocysts: Clinical Features: Oral and Maxillofacial Surgery Clinics of North America, 2003; 15(3): 335345 .

[25]. Tolstunov L, Treasure T: Surgical treatment algorithm for Odontogenic Keratocyst: Combined treatment of Odontogenic Keratocyst and mandibular defect with marsupialization, enucleation, iliac crest bone grafts and dental implants. Journal of Oral and maxillofacial Surgery, 2008;66: 1025-1036

[26]. Donkor P, Punnia-Moorthy A. Biochemical analysis of simple bone cyst fluid: report of a case. Int J Oral Maxillofac Surg 1994; 23 : 296-297.

[27]. Suei Y, Taguchi A, Kurabayashi T, Kobayashi F, Nojiri M, Tanimoto K. Simple bone cyst: investigation on the presence of gas in the cavity using computed tomography. Oral Surg Oral Med Oral Pathol 1998; 86: 592-594.

[28]. Suei Y, Taguchi A, Tanimoto K. Simple bone cyst of the jaws: evaluation of treatment outcome by review of 132 cases. J Oral Maxillofac Surg. 2007; 65: 918-923.

[29]. Narang R, Jarrett JH. Large traumatic bone cyst of the mandible. J Oral Surg 1980; 38: 617-618

[30]. Ferreira Júnior FO, Damante JH, Lauris JR. Simple bone cyst versus odontogenic keratocyst: differential diagnosis by digitized panoramic radiography. Dentomaxillofac Radiol. 2004; 33: 373-378

[31]. Matsumura S, Murakami S, Kakimoto N, Furukawa S, Kishino M, Takeshi I et al. Histologic and radiographic findings of the simple bone cyst. Oral Surg Oral Med Oral Pathol Oral Radiol Endod. 1998; 85: 619-625.

[32]. Lokiec F, Wientroub S. Simple bone cyst: etiology, classification, pathology, and treatment modalities. J Pediatr Orthop B. 1998; 7: 262-273.

[33]. Segev Y, Puterman M, Bodner L. Stafne bone cavity - Magnetic resonance imaging Med Oral Patol Oral Cir Bucal 2006;11: 345347

[34]. Katz J, Chaushu G, Rotstein I. Stafne's Bone Cavity in the Anterior Mandible: A Possible Diagnostic Challenge Journal Of Endodontics 2001;27: 304-307

[35]. Ariji E, Fujiwara N, Tabata O, et al. Stafne's bone cavity: Classification based on outline and content determined by computer tomography Oral Surg Oral Med Oral Pathol 1993;76: 375-380

[36]. Shields ED. Technical note: Stafne static mandibular bone defect - further expression on the buccal aspect of the ramus. Am J Phys Anthropol 2000; 111: 425-427 